\title{
Effects of Superplasticizing Admixtures on the Compressive Strength of Concrete
}

\author{
Musbah Guma Musbah, Allam Musbah Al Allam*, Hosni Abdulruhman Saleh, \\ Ibrahim Mousbah Ateeg \\ College of Technical Sciences, Bani Walid, 00218, Libya
}

Copyright $\bigcirc 2019$ by authors, all rights reserved. Authors agree that this article remains permanently open access under the terms of the Creative Commons Attribution License 4.0 International License

\begin{abstract}
Nowadays, the most widely used construction materials in the market for both structural and non-structural applications are concrete-based. Concrete in general is made up of a combination of cement, aggregate, water and an additional material known as an admixture. The admixture is sometimes added to modify certain properties of concrete. Superplasticizer (SP) is one type of the admixtures, which was used for this study to modify the properties of concrete. Correct composition of admixture is important as usage of incorrect admixture, mix proportion and improper dosage of SP might cause high-slump concrete, bleeding, segregation and cracking due to shrinkage. Therefore, this project aimed to determine the optimum dosage of SP for normal strength concrete by studying the effects of three different dosages of SP, (500, 750 and $1000 \mathrm{ml} / 100 \mathrm{~kg}$ ) on properties of concrete in fresh and hardened state. Two series of concrete mix consisting of eight samples for both grades C25 and C30 were prepared for the experimental work. The control mix (without SP) was designed based on the DOE method. One type of specimen was used in different quantity. As a result, the optimum dosage of SP for the studied concrete properties was $750 \mathrm{ml} / 100 \mathrm{~kg}$ of cement for both grades C25 and C30. Some comparative analyses were done to determine the relationships between the various parameters. It was found that the mechanical properties of the concrete mix with optimum SP, namely the compressive strength is higher than the control specimens. It was also found that the physical properties of the concrete mix with the optimum SP dosage improve workability.
\end{abstract}

Keywords Normal Concrete, Admixtures, Superplasticizer (SP), Optimum Dosage of (SP), DOE Method, Compressive Strength

\section{Introduction}

The usage of admixtures such as superplasticizers in concrete technology has created a revolution in producing concrete with lower water/cement ratio compared to the standard without jeopardizing the original strength and workability. However, there are still uncertainties on the exact quantity and quality of the admixtures used due to inadequate data that explains the effects of using these admixtures on the strength and workability of the concrete. Therefore, in Malaysia, about 90-95 percent of the construction materials market for both structural and non-structural applications is made of concrete compared with other materials used for similar functions [1]. Concrete, generally, is a product made from cement, water and aggregates and an additional material known as admixture, is sometimes added to modify certain properties of concrete. Cement is the chemically active constituent but its reactivity is only brought into effect upon mixing with water. The aggregate plays no important roles in chemical reaction but its usefulness arises because it is an economical filler material or hard composite material with good resistance to volume changes which take place within the concrete after mixing, besides improving durability of concrete [2]. In hardened state, concrete is a rock like material with a high compressive strength. In its plastic state, concrete may be molded into any form of shapes, it may be used to advantages architecturally or solely for decorative purposes. Concrete has low tensile strength, and hence, this is the reason why it is used with steel bar to resist any tensile forces in the reinforced concrete [2]. Concrete is usually used in building for foundations, columns, beams and slabs, in shell structures, bridges, sewerage treatment plants, roads, cooling towers, railway sleepers and so on. In precast concrete industry, concrete is widely used as concrete blocks, cladding panels, pipes, piles and lamp posts [2]. Nowadays, more than $70 \%$ of in-situ concrete in Malaysia is produced by the ready mixed concrete industry. The ready mixed concrete producers are using superplasticizing (SP) admixtures which are readily available from various manufacturers [3]. According to Dodson , 1990 one of the first materials used to be mixed with concrete was black carbon (1930) where 
it was used as dye (Naphthalene Sulfonate) and was also reported to increase the strength of concrete roads in one of the projects in America at that time [4]. In Japan, (Kikuwa Hitori, 1990) discovered a new admixture consisting of Bnapthalane that lowers the water/cement ratio but increases the concrete strength [5]. Meanwhile, in Germany, Isenberg (1974) also introduced an admixture type Melamine Sulfonate to improve the workability of concrete while maintaining the water/cement ratio without affecting its strength [6]. Also, the addition of plasticized admixture is able to reduce the water content of concrete to up to $25 \%$ whilst doubling the compressive strength compared to traditional concrete on day one. Besides that, it can achieve a third of 28 days strength [7]. Superplasticizer is a type of water reducers; however, the difference between superplasticizer and water reducer is that superplasticizer will significantly reduce the water required for concrete mixing [8]. There are two common categories of superplasticizers; sulfonated melamine formaldehyde condensates and sulfonated naphthalaneformaldehyde condensates. superplasticizers are water-soluble organic polymers which have to be synthesized to produce long molecules of high molecular mass [9].

\section{Materials and Methods}

Concrete is a composite of cement, aggregate (fine and coarse) and water. Sometimes, chemical or mineral admixtures are added in order to change the characteristics of concrete for certain applications. Since the materials are important in determining the quality of produced concrete, they should be properly selected and chosen before the beginning of the experiment.

\subsection{Ordinary Portland Cement}

The cement used in this project is a product from cement industries of Malaysia berhad (CIMA), with a brand name holcim top standard"e. This type-i cement conforms to MS 522: 2007, where it is high quality multi-purpose cement suitable for all buildings and construction purposes. When mixed with send and water to form mortar, it is ideal for brick laying and rendering, or with added coarse aggregate to form concrete for flooring. Also it is widely used in general construction, for example buildings, bridges and other precast concrete products. It is available in $50 \mathrm{~kg}$ bags. The chemical amount constituents in ordinary Portland cement

\subsection{Aggregate}

Aggregate is important because it occupies about threequarters of the volume of concrete. Usually, there are two types of aggregate used in concrete, which are fine and coarse aggregates. Many parameters needed to be considered in selection of aggregate, for instance, types of aggregate, size and shape of the particle, and the strength of the aggregate. All aggregate must be free from dust as the dust may affect the bonding between the aggregate and cement particles.

\subsection{Mixing Water}

Water is important to ensure continuous hydration process. Along the experiment, tap water is used for mixing and curing of concrete. The water must be free from reactive elements such as reactive ions and impurities to guarantee the quality of the concrete.

\subsection{Chemical Admixtures}

The type of admixtures used in this study, namely superplasticizer. Since the objective of this experiment is to observe the effects of these admixtures on the concrete characteristics, hence, both physical and chemical properties must be known to have a better understanding on the effect of admixtures.

\subsection{Concrete Mixtures}

The design mix in this study is based on the department of the environment (DOE) United Kingdom. Selecting the correct proportions of cement, fine, and coarse aggregate and water to produce concrete having the specified properties is a basic problem in designing a concrete mix. Hence the design mix is very important in achieving the design characteristic strength.

\section{Method of Design}

For this project there are two types of grades $\mathrm{c} 25$ and c 30 . The mixtures designed individually each mix with different steps based on (DOE) method. Basically, the problem of designing a concrete mix consists of selecting the concrete proportions of cement, fine and coarse aggregate, water and admixtures to produce concrete having the specified properties [10]. Tests were carried out in order to investigate the properties of the concrete. Basically, there are three types of testing, namely control testing, compliance testing and secondary testing. Control testing is used to ensure acceptable supplied materials are available, whereas, compliance testing is to judge compliance of the material with the given specifications. Lastly, secondary testing is used when there is doubt about the reliability of control and compliance results, [11].

\subsection{Mix Proportions and Specimens}

Tow series of concrete mix consists of grade c 25 and c 30 were prepared for the experimental work. The mix proportions of the control mixes without (sp) will be 
determined based on (doe) method. SP with the dosage of $500 \mathrm{ml} / 100 \mathrm{~kg}$ of cement, $750 \mathrm{ml} / 100 \mathrm{~kg}$ of cement and $1000 \mathrm{ml} / 100 \mathrm{~kg}$ of cement was used as admixtures to prepare another six different mixtures. A size of (100 $\mathrm{mm} * 100 \mathrm{~mm}$ ) cube with a number of 15 cubes was prepared to test the compressive strength for each mix.

\subsection{Design Stages for (DOE) Method}

In order to clarify the sequence of operation, and for ease of reference, the flow process is divided in to five stages. Each of these stages deals with a particular aspect of the design and ends with an important parameter or final unit proportions. The table below shoes the volume of concrete for each batch for both grade $\mathbf{C 2 5}$ and $\mathbf{C 3 0}$.

Table 1. The volume of concrete for each batch for both grade $\mathrm{C} 25$ and C30

\begin{tabular}{|c|c|c|c|c|}
\hline Grade C25: & & & & \\
\hline Quantities & $\begin{array}{c}\text { Cement } \\
(\mathrm{kg})\end{array}$ & $\begin{array}{l}\text { Water } \\
\text { (liter) }\end{array}$ & $\begin{array}{c}\text { Fine agg. } \\
(\mathrm{kg})\end{array}$ & $\begin{array}{l}\text { Coarse agg. } \\
(\mathrm{kg})\end{array}$ \\
\hline Per $1 \mathrm{~m} 3$ & 309 & 210 & 602 & 1279 \\
\hline \multicolumn{5}{|l|}{ Grade C30 } \\
\hline Quantities & $\begin{array}{c}\text { Cement } \\
(\mathrm{kg}) \\
\text { Water } \\
\text { (liter) }\end{array}$ & $\begin{array}{l}\text { Fine } \\
\text { agg. } \\
(\mathrm{kg})\end{array}$ & $\begin{array}{l}\text { Fine agg. } \\
\quad(\mathrm{kg})\end{array}$ & $\begin{array}{l}\text { Coarse agg. } \\
\quad(\mathrm{kg})\end{array}$ \\
\hline Per $1 \mathrm{~m} 3$ & 323 & 21 & 597 & 1270 \\
\hline
\end{tabular}

\section{3. Compressive Strength Test}

Compressive strength is the most common test performed on concrete according to (Part 14 testing of hardened concrete). The several reasons for this are: 41 1)
It is assumed that the most important properties of concrete as directly related to compressive strength. 2) Concrete has little tensile strength and is used primarily in compression. 3) Structural design codes are based on compressive strength. After curing the samples of $(100 * 100 \mathrm{~mm})$ cube, which were casted at the first day of the excremental work. Fifteen cubes for each mix (three for each period) were tested on the compressive strength test at 7, 14, 28, 56 and 90 days, respectively.

\section{Results and Discussion}

\subsection{Compressive Strength of Concrete Specimens with Grade 25}

Table2. Compressive Strength of Concrete Specimens with Grade 25

\begin{tabular}{|l|l|l|l|l|l|}
\hline Mix ID & \multicolumn{5}{|l|}{ Compressive Strength (MPa) } \\
\hline & 7 days & 14 days & 28 days & 56 days & 90 days \\
\hline M1 & 18 & 23.8 & 26 & 33 & 33 \\
\hline M2 & 19.6 & 22.5 & 28 & 31 & 31.5 \\
\hline M3 & 20 & 24 & 32 & 33.5 & 36 \\
\hline M4 & 18.9 & 23.5 & 25.5 & 30.5 & 30.5 \\
\hline
\end{tabular}

Figure 1 represents the compression strength for the mixtures with grade $\mathrm{C} 25$. Which, indicate the relation between the age of samples in (day) and the maximum load effects the samples in (MPa). As shown above in figure 1 there is an increase for all samples with increase of age. Therefore, (M3) is the mix with dosage of $(750 \mathrm{ml} / 100 \mathrm{~kg}$ of cement) contains the biggest value of compressive strength with $(36 \mathrm{MPa})$ at 90 days.

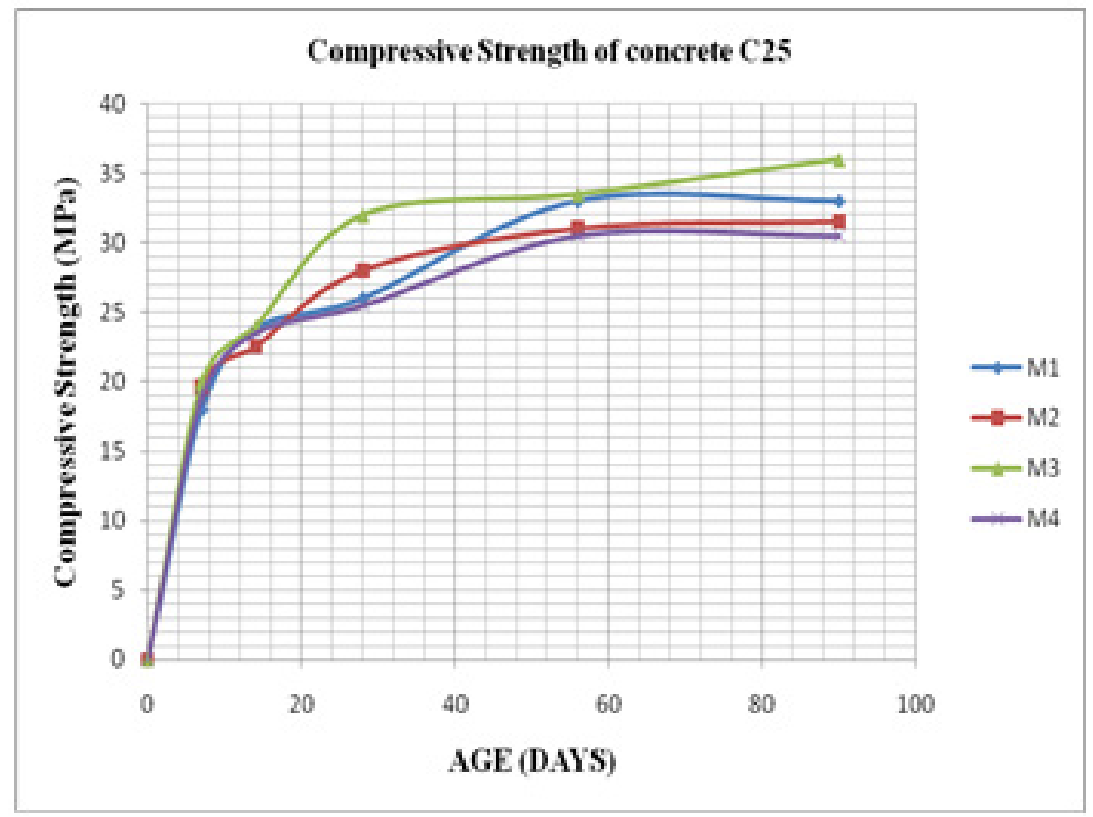

Figure 1. Compressive Strength of Concrete C25 


\subsection{Compressive Strength of Concrete Specimens with Grade 30}

Figure 2 represents the compression strength for the mixtures with grade $\mathrm{C} 30$. Which, indicate the relation between the age of samples in (day) and the maximum load effects the samples in (MPa). As shown above in figure 2 there is an increase for all samples with increase of age. Therefore, (N3) is the mix with dosage of (750ml/100kg of cement) contains the biggest value of compressive strength with $(40.7 \mathrm{MPa})$ at 90 days. On the other hand, (N4) the mix with dosage of $(1000 \mathrm{ml} / 100 \mathrm{~kg}$ of cement) has the smallest compressive strength with $(30 \mathrm{MPa})$ at the same day.

Table 3. Compressive Strength of Concrete Specimens with Grade 30

\begin{tabular}{|c|c|c|c|c|c|}
\hline Mix ID & \multicolumn{5}{|c|}{ Compressive Strength (MPa) } \\
\hline & 7 days & 14 days & 28 days & 56 days & 90 days \\
\hline N1 & 16.7 & 22.5 & 31 & 31 & 31 \\
\hline N2 & 16 & 20 & 33 & 33 & 33 \\
\hline N3 & 24.2 & 29.4 & 37 & 37.8 & 40.7 \\
\hline N4 & 16.5 & 23 & 30 & 30 & 30 \\
\hline
\end{tabular}

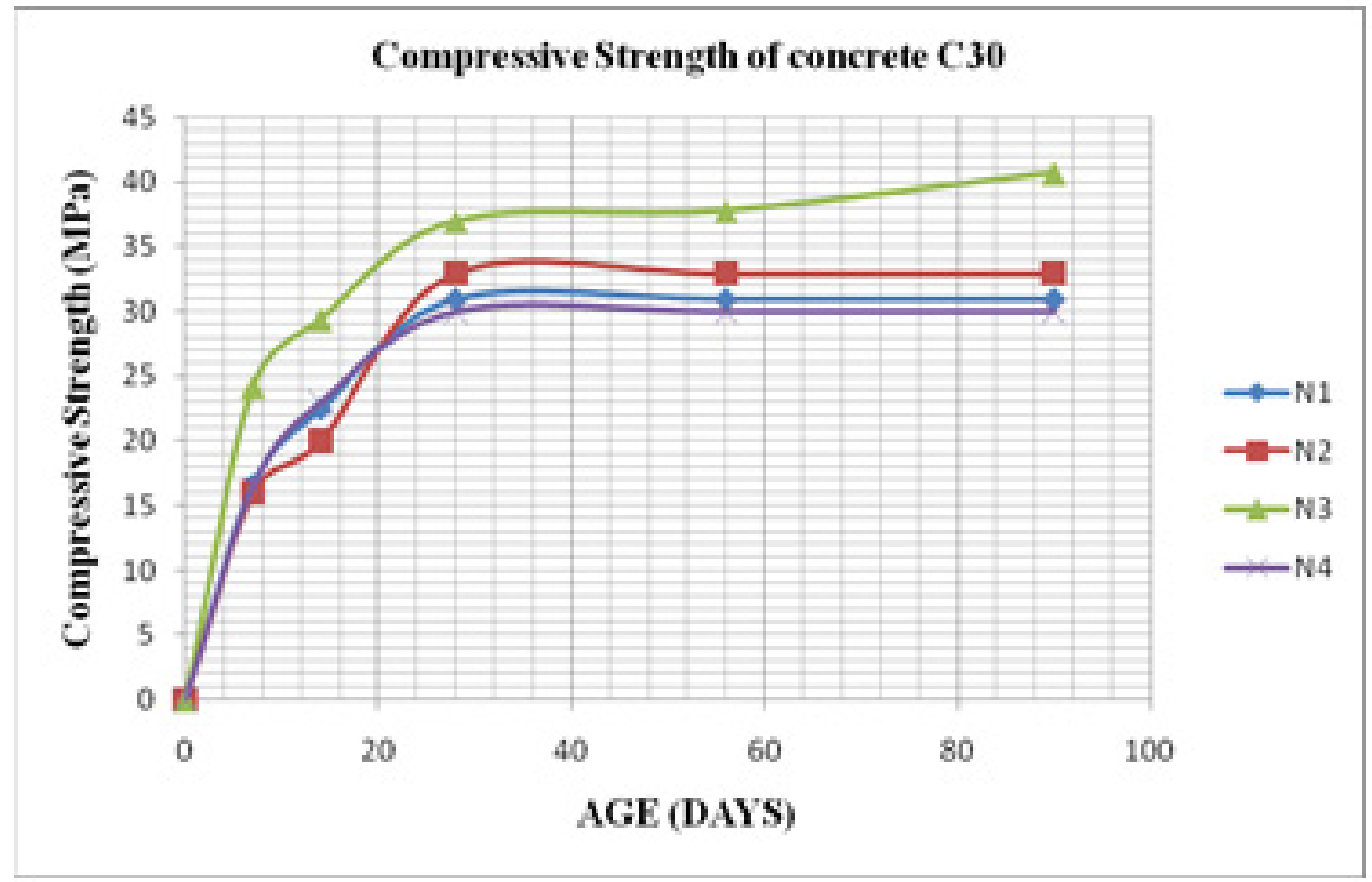

Figure 2. Compressive Strength of Concrete C30

\subsection{Relationship between Workability and Compressive Strength at 28 Days due to Different Dosage of (SP)}

Based on the previous studies there is a strong relationships between workability and compressive strength of the concrete. However, there are few studies about this relationship which described by different researchers below: In Germany, Isenberg (1974) also introduced an admixture type Melamine Sulfonate to improve the workability of concrete while maintaining the water/cement ratio without affecting its strength [6]. Figures 3 and 4 represent the relationship between workability and compressive strength at 28 days due to different dosage of (SP). Therefore, Figure 3 describes the relationship between slump value and (SP) dosage for grade C25 and C30. 


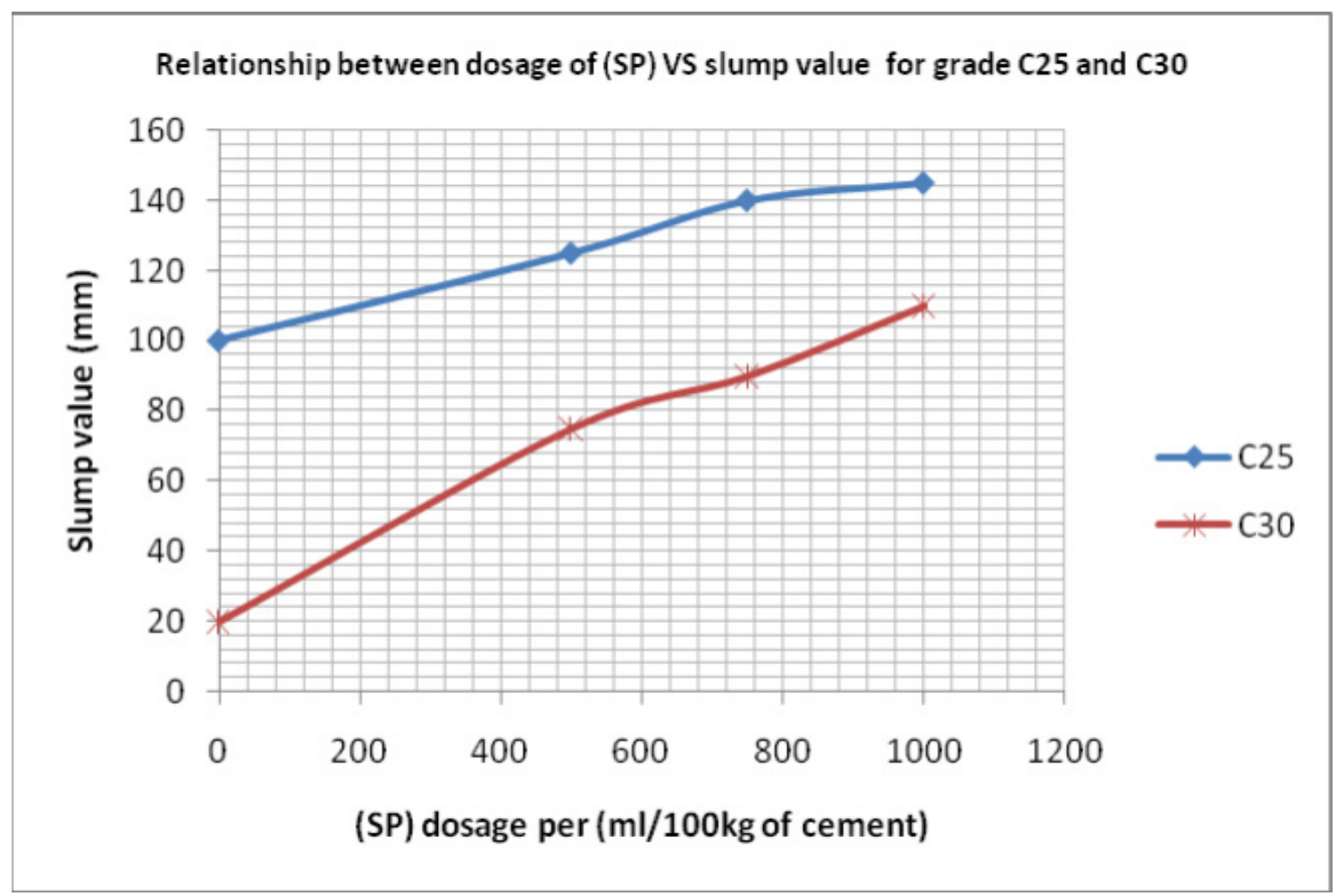

Figure 3. The Relationship between the Slump value and (SP) Dosage for grade C25 and C30

Figure 3 above shows the relationship between slump value and (SP) dosage used for this project with both grades $\mathrm{C} 25$ and $\mathrm{C} 30$. As shown, that there is a gradual increase for the two curves. In additional, the increase of slump value describes the increase of the concrete workability. Therefore, both grades represent high workability with increase of (SP) dosage. For example, the blue curve represents the workability for $\mathrm{C} 25$ with a minimum value of slump of $(100 \mathrm{~mm})$ with dosage of $(500$ $\mathrm{ml} / 100 \mathrm{~kg}$ of cement) and maximum of $(145 \mathrm{~mm})$ with dosage of $(1000 \mathrm{ml} / 100 \mathrm{~kg}$ of cement). On the other hand, the red curve describes the workability for $\mathrm{C} 30$ with a minimum slump of $(20 \mathrm{~mm})$ with dosage of $(500 \mathrm{ml} / 100 \mathrm{~kg}$ of cement) and maximum of $(110 \mathrm{~mm})$ with dosage of $(1000 \mathrm{ml} / 100 \mathrm{~kg}$ of cement).
As shown in figure 4 there is an increase of compressive strength with an increase of slump value for both grades C25 and C30 until certain value of slump which than follows a slight decrease for compressive strength. In conclusion, the finding was obtained from the relationship is described by the following: 1.Adding (SP) on normal concrete improved the workability. 2. There was an increase of slump value with an increase of (SP) dosage. From the graphs above there was an increase of compressive strength with the optimum dosage of (SP) which found that the optimum dosage was $(750 \mathrm{ml} / 100 \mathrm{~kg}$ of cement) for both grades $\mathrm{C} 25$ and $\mathrm{C} 30$. 3. The results found from this research were similar to (Nagasaki, 1997) and (ACI 212-3R). 


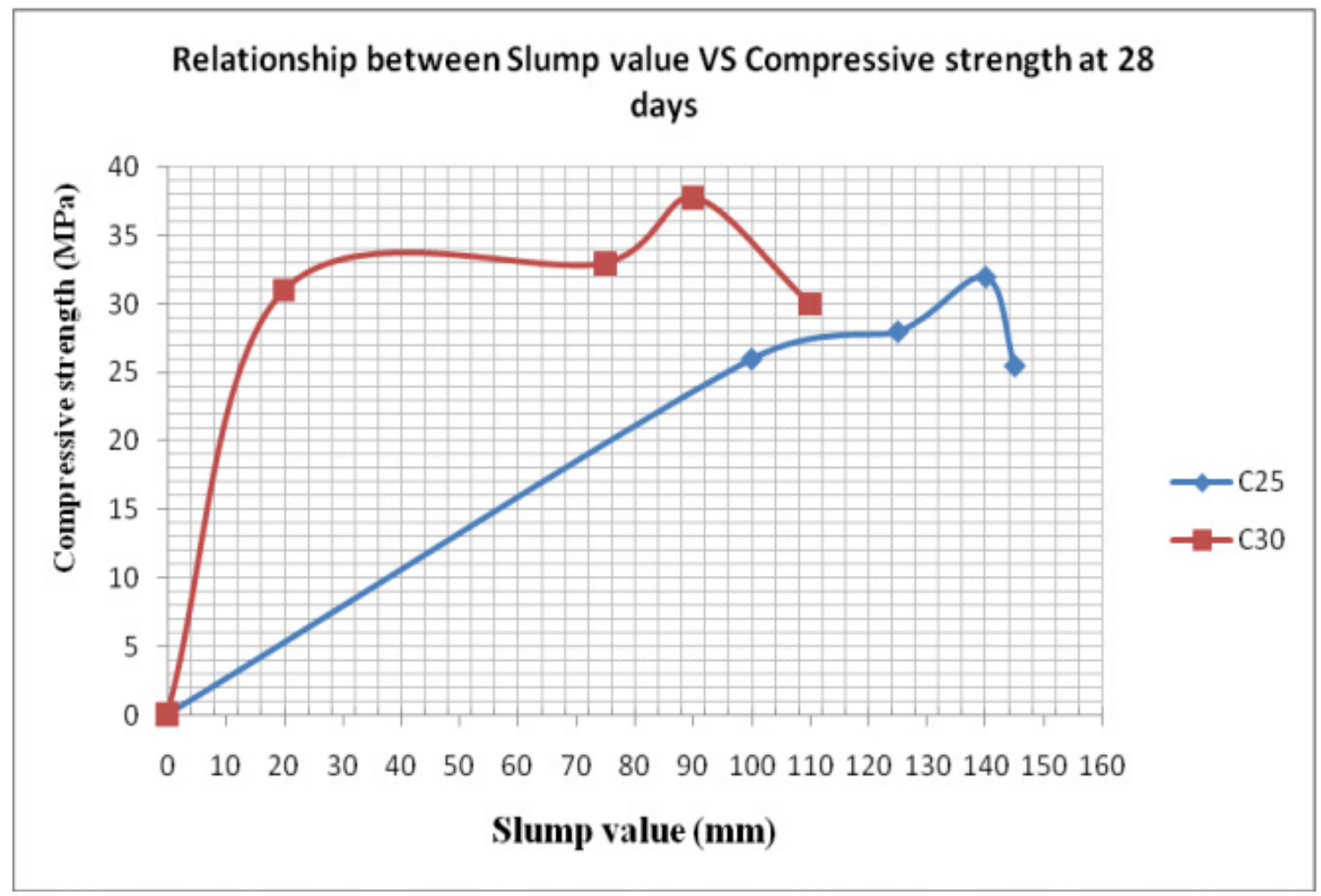

Figure 4. The Relationship between the Slump value and Compressive Strength at 28 days for grade C25 and C30

\section{Conclusions}

Taking into account the findings from this study, previously presented, the following conclusions can be drawn:

1. The study represented the effect of superplasticizer (SP) on the mechanical and physical properties of concrete with both grades $\mathrm{C} 25$ and $\mathrm{C} 30$.

2. The mechanical property tested was (Compressive, Strength) for grade $\mathrm{C} 25$ and C30. 2. The physical property tested for this study in both grades $\mathrm{C} 25$ and C30 was. Workability (on the fresh state).

3. The dosage of (SP) were used is $(500,750$, and 1000 $\mathrm{ml} / 100 \mathrm{~kg}$ of cement) for both grades $\mathrm{C} 25$ and $\mathrm{C} 30$.

4. The optimum dosage of (SP) added was (750 $\mathrm{ml} / 100 \mathrm{~kg}$ of cement) for all of the findings in both grades $\mathrm{C} 25$ and $\mathrm{C} 30$.

5. From the relationships between the properties the obtaining was as follow:

a). The effect of (SP) on normal concrete improved the workability.

b). The maximum compressive strength met with the optimum dosage of (SP) at $(750 \mathrm{ml} / 100 \mathrm{~kg}$ of cement) for both grades $\mathrm{C} 25$ and $\mathrm{C} 30$.

c). The maximum increase in percentage when compared with the control mix at 28 days is $23 \%$ for compressive strength, for grade $\mathrm{C} 25$ at the optimum dosage.

d). The maximum increase in percentage when compared with the control mix at 28 days is $22 \%$ for compressive strength, for grade $\mathrm{C} 30$ at the optimum dosage.

e). There was a decrease of water content with different dosage of (SP) which the maximum decrease in water content was $30.6 \%$ at 90 days for $\mathrm{C} 25$ and $26.7 \%$ at 90 days for $\mathrm{C} 30$.

f). All of the tested samples for this study met the (BS.1881: part 122: 1983) standers and have absorption rate below $10 \%$.

\section{Acknowledgements}

Thanks to my supervisor Dr. Hj. Zainal Abidin Bin Akasah, for his help and guidance in me finishes this research successfully. Special thanks to my co. Supervisor Mr. Koh Heng Boon for his supervision, encouragement, contradictive ideas, patience, guidance and invaluable advice, enabling me to achieve the objective of this research

All so, I would like to acknowledge the contributions and the financial support by Collage of Technical Science-Bani Walied Libya.

\section{REFERENCES}

[1] Hassan and Hamzah (2004). Concrete durability issues in the Malaysian construction industry. 5th Short Coarse on 
Concrete Durability, Assessment, Maintenance and Repair Techniques, Oct. 4- 6. W. Zabierowski, A. Napieralski. Chords classification in tonal music, Journal of Environment Studies, Vol.10, No.5, 50-53.

[2] Jackson, N. and Dhir, R. K (1996). Civil Engineering Materials. Hampshire, U.K.: Palgrave Publishers Ltd.

[3] Stillwell, J. A (1984). Current Practice Sheets - Volume 1." The Concrete Society.: London, U. K

[4] Dodson, V.H. (1990). Concrete Admixture, Structural Engineering Series,ed. Nostrand Rheinhold, New York, USA.

[5] Kikuwa Hitori (1990), "Rheological studies on fresh concrete using admixtures" Proc. RILEM, Symp, Admixtures for concrete improvement properties.

[6] Nagasaki, S. (1997). Present State of Superplasticizer in Japan, Conf. Paper on Plasticizers and Other Chemical Admixtures, Rome, Italy.

[7] Jones T.P, (1982). Concrete Technology 4, Vol. 1 Properties and Materials.

[8] Neville A.M (2005). Properties of concrete, Pearson. Prentice Hall, p 255- 262.

[9] A.M. Neville (2002). Properties of Concrete

[10] Teychenne. D. C (1988). Design of normal concrete mix. Building Research Establishment, Watford.

[11] Bungey, J. H. and Millard S. G., (1996). Testing of concrete in structures. Chapman \& Hall.

[12] Neville A. M. and J. J. Brooks (1987). Concrete technology. Longman. p. 83- 86, 89- 90.

[13] T. Seshadri Sekhar and P. Srinivasa Rao (2008). Relationship between Compressive, Split Tensile, Flexural Strength of Self Compacted Concrete. International Journal of Mechanics and Solids ISSN 0973-1881 Volume 3Number 2, pp. 157-168 C Research India Publications _. 